\title{
Of new times, new opportunities, and old problems
}

\author{
Johan van der Lei · Miriam Sturkenboom
}

Received: 12 April 2007/Accepted: 17 April 2007/Published online: 26 May 2007

(C) Springer Science+Business Media B.V. 2007

It does not require rocket science to observe the enormous impact Information and Communication Technology (ICT) has on our society. High expectations are placed on the increased use of ICT in health care [1]. The American Institute of Medicine, for example, argues that efficient, high quality healthcare mandates the use of well-developed ICT applications including electronic patient records that replace the paper records [2]. Others believe that the application of ICT constitutes "the future salvation of evidence-based medicine" : ICT is, in their opinion, able to provide the much-needed mechanisms that will allow the large-scale implementation of recommendations and guidelines in day-to-day care [3]. The term "rapid-learning health system" has been introduced to describe a healthcare system that is able to rapidly learn from medical experience using an extensive ICT infrastructure [4]. And many hitherto frequently-used terms receive an addition: the "e-"' is added resulting in e-health, e-science, e-consult, e-surgery, e-epidemiology, and so on and so forth.

The new opportunities provided by the internet for researchers investigating a population are detailed in two contributions in this issue $[5,6]$. In essence: the Internet is a mechanism to contact the population. As a mechanisms to contact the population, the Internet has a number of clear advantages; it allows, for example, the tailoring and opti-

J. van der Lei $(\bowtie) \cdot$ M. Sturkenboom

Department of Medical Informatics, Erasmus MC University Medical Centre, Rotterdam, The Netherlands

e-mail: j.vanderlei@erasmusmc.nl

M. Sturkenboom

Department of Epidemiology and Biostatistics, Erasmus MC University Medical Centre, Rotterdam, The Netherlands mizing of questionnaires (e.g., experimentation with different layouts or branching logic), monitoring the process of filling in the questionnaire (including plausibility and consistency checking), and monitoring response (e.g., lurkers that have partially answered questionnaires are available for follow-up). And when a large study has to be conducted: all of this flexibility for a much lower financial cost than paper-based questionnaires. The Internet as a mechanism to survey a population, therefore, should be a tool in the toolbox of the modern epidemiologist. These papers underscore the importance of ICT or the Internet for epidemiological research. ICT for an individual epidemiologist can be both a tool to collect data from subjects (in this paper: the population that is subject of the study) and a source of data (e.g., electronic patients records in an observational data base). To reflect on the role in the Internet as a tool in the toolbox of the modern epidemiologist, we believe it is important to understand not only the new aspects of the Internet, but also recognize that, as the saying goes, "the more things change, the more they stay the same".

It has always been the strength of epidemiology as a research endeavor that it emphasizes, promotes and studies the very tools it relies on to perform its research. Epidemiologists know that in order to interpret the data appropriately, they need to understand how the data came into existence. The engineer knows that in order to use a measuring device, the device needs to be calibrated. Likewise the epidemiologist will have to assess the promises and pitfalls of his/her data collection methods and tools. And for an increasing number of epidemiologists this will include Internet-based methods.

Assessing the specific properties of Internet-based tools for collecting data is not an easy task. As pointed out by 
Ekman et al, paper-based questionnaires cannot be the gold standard for their internet-based counterparts [6]. Studies will therefore typically focus on comparison (e.g., scoreequivalence when internet and paper are compared in a randomized trial) rather than using paper as gold standard (e.g., 7-12). Specific properties of the medium Internet are studied and initial results are emerging. Some researchers report that certain types of data (e.g., risky behavior) are reported differently on the Internet than on paper-possibly the internet is perceived as more anonymous when compared to a paper-based questionnaire. As our understanding of the Internet as a tool to survey a population increases, we will be able to decide, based on our understanding of the tools involved, when paper or Internet is the more appropriate tool.

Litton draws an analogue with the introduction of book printing [5]. By replacing the written word with the printed word, a fundamental change occurred. Although the content remained the same, the fact that the content was multiplied thousand fold by the ability to print the book rather than painstakingly manual copying created a whole new environment. In order to understand the impact of book printing, one must see beyond the mere fact that the same text could be reproduced manifold. Subsequent years saw not only changes in the structure of the society, but also new, previously unknown issues emerged. The notion of copyright, for example, was a direct result of printing. Prior to the ability to print, copyright was unheard of. Likewise, the change from a paper-based environment to an electronic-based environment will set a chain of events in motion. That chain of events, however, is just beginning to unfold. The change from paper to electronic carriers is visible both in medical care (e.g., electronic patient records) and research (e.g., systems to conduct trials). The initial events will focus on replacing paper documents. That is, paper is replaced by an electronic version of that paper-typically, with some added flexibility and speed. The paper of Ekman et al. [6] falls in this category: paper questionnaires are replaced with electronic counterparts, and flexibility is increased. Socio-technical researchers emphasize that this initial stage focused on replacing paper is only the beginning [13]. Processes (be it health-care delivery or research) are analyzed in detail in order to support these processes with ICT. Boundaries between different professionals are investigated, sometimes removed, but always re-defined. Responsibilities are re-assigned. And high expectations of the final outcome this process re-design are expressed [1, 2, 4].

Although the overwhelming majority of researchers emphasize the potential positive impact of ICT on health care and research, a number of writers have persistently voiced their concern. Already decades ago, the first publications on the potential negative impact of multiple use of (medical) data in electronic environments appeared. Burnum [14], for example, in a paper entitled "The misinformation era: The fall of the medical record", stated that " with the advent of the information era in medicine, we are pouring out a torrent of medical record misinformation'. He argued that, although paper medical records have long been faulty, computer-based medical records would contain even more distorted and misleading information. He concluded that "all medical record information should be regarded as suspect; much of it is fiction', The crux of Burnum's reasoning is that medical data are not real-life entities. As the German states: data do not exist " an sich'. Medical data are the consequence of humans' interpretation or observing the world (or deciding to measure entities in that world). As a result, Burnum could argue that medical data are inherently subjective and that the indiscriminate use of that data for multiple purposes would result in mis-information. Although Burnum's position is not shared by other investigators to the same extent, it does point out that a careful consideration of the impact of ICT in the process of creating data and information is required.

It is our belief that in coming years, the decades of experience epidemiologists have in analyzing their own research tools will be put to good use in studying the research tools that are emerging in the Internet age. We can only underscore Ekman's view that new opportunities and tools are emerging. We are indeed on the threshold of an exciting new era characterized by our ability to collect, store, communicate and analyze massive amounts of data. But underneath the surface, old problems lurk: essential for a correct interpretation of data is a keen understanding of the processes that created the data to begin with.

\section{References}

1. Bates DW, Gawanda AA. Improving safety with information technology. N Engl J Med 2003;348:2526-34.

2. Institute of Medicine. Crossing the quality chasm: a new health system for the 21 st century. Washington D.C.: National Academic Press; 2001.

3. McNeely MD. The use of expert systems for improving test use and enhancing the accuracy of diagnosis. Clin Lab Med 2002;22(2):515-28.

4. Etheredge LM. A rapid-learning health system. Health Aff (Millwood) 2007;26(2):w107-18.

5. Ekman A, Litton J. New times, new needs; e-epidemiology. Eur J Epidemiol 2007;22(5):285-92.

6. Ekman A, Klint A, Dickman PW, Adami H, Litton J. Optimizing the design of web-based questionnaires: experience from a population-based study among 50,000 women. Eur J Epidemiol 2007;22(5):293-300.

7. Bloom DE. Technology, experimentation, and the quality of survey data. Science 1998;280(5365):847-8.

8. Mangunkusumo RT, Moorman PW, Van Den Berg-de Ruiter AE, Van Der Lei J, De Koning HJ, Raat H. Internet-administered 
adolescent health questionnaires compared with a paper version in a randomized study. J Adolesc Health 2005;36(1):70 e 1-6.

9. Pouwer F, Snoek FJ, van der Ploeg HM, Heine RJ, Brand AN. A comparison of the standard and the computerized versions of the Well-being Questionnaire (WBQ) and the Diabetes Treatment Satisfaction Questionnaire (DTSQ). Qual Life Res 1998;7(1):33-8.

10. Raat H, Mangunkusumo RT, Mohangoo AD, Juniper EF, Van Der Lei J. Internet and written respiratory questionnaires yield equivalent results for adolescents. Pediatr Pulmonol 2007;42(4):357-61.

11. Turner CF, Ku L, Rogers SM, Lindberg LD, Pleck JH, Sonenstein FL. Adolescent sexual behavior, drug use, and violence: in- creased reporting with computer survey technology. Science 1998;280(5365):867-73.

12. Webb PM, Zimet GD, Fortenberry JD, Blythe MJ. Comparability of a computer-assisted versus written method for collecting health behavior information from adolescent patients. J Adolesc Health 1999;24(6):383-8.

13. Berg M, Aarts J, van der Lei J. ICT in health care: sociotechnical approaches. Methods Inf Med 2003;42(4):297-301.

14. Burnum JF. The misinformation era: the fall of the medical record. Ann Intern Med 1989;110(6):482-4. 